\title{
Modular Design of Floating Surface Leisure Platforms
}

\author{
Lili Dong ${ }^{1}$, Xiang Cheng ${ }^{1}$, Wei Wang ${ }^{2 *}$ \\ ${ }^{1}$ School of Architecture and Urban Planning, Chongqing Jiaotong University, Chongqing 400074, China \\ ${ }^{2}$ School of Art, Design and Architecture, University of Huddersfield, Queensgate, Huddersfield, HD1 3DH, West Yorkshire, \\ United Kingdom
}

Corresponding Author Email: wangwei19930801@foxmail.com

https://doi.org/10.18280/ijdne.150213

Received: 17 October 2019

Accepted: 29 January 2020

\section{Keywords:}

water area tourism, water surface leisure platform, modular design, ecological floating bed

\begin{abstract}
The development of water area tourism has prompted the upgrading of water surface platforms. Researchers have been carrying out studies, attempting to optimize the design of floating surface leisure platforms through modularization. This paper first analyzes the advantages and bottlenecks of floating leisure platform products for the development of water area tourism, and then applies modular design to optimize the ecological floating bed into a structure consisting of standardized functional components incorporated into the cavities of the floating boxes in the platform, which expands the ecological functions of the platform. This paper also optimizes the design of the modular platform components to improve the economic efficiency of product packaging and transportation, the convenience of platform building and the stability of the platform. The design provides a new idea and choice for the upgrading of floating platforms.
\end{abstract}

\section{INTRODUCTION}

Various types of water bodies have formed different water landscapes under the interactions of geology, climate, biology and human activities [1]. With the rapid growth of the tourism industry, water area tourism has ushered in an opportunity for further development due to the special experience it brings to tourists. Water surface leisure platforms, as a key access to water areas, also need to be upgraded to achieve ecological functions, make the construction process more efficient and economic and adapt to different scenarios. Floating platforms using floating boxes as the floating base are now being widely applied in the industrial transformation and development of water area tourism as a replacement of the fixed leisure platforms with reinforced concrete and wood as the fixed base. However, the current floating platforms have only one function and are hardly expandable, which are apparently not good enough for the development of water area tourism in the face of water pollution. Therefore, it would be a useful attempt to design and build a kind of water surface leisure platform that is more flexible and able to purify water so as to restore and effectively control eutrophic water and at the same time promote the sustainable development of water area tourism.

The research on water environmental protection during water resources development started quite early. In the 1930s, France put forward the idea of ecological river remediation, which emphasizes environmental protection and water tourism development in engineering construction. Then Britain, Germany and other countries successively proposed the concept that rivers should be closer to their natural state $[2,3]$. Regarding the ecological floating bed technology for water environment treatment, American ecologist Gurney was the first scholar to study floating islands. Afterwards, Alam et al. [4], Haller [5], Mallison et al. [6], Sasser et al. [7, 8] also conducted studies on artificial floating islands. In 1980,
German scholar Sven Hoeger designed a modern ecological floating bed and applied it for the first time to purify polluted water. In 1998, he published the famous paper Schwimmkampen: Germany's Artificial Floating Islands. In the paper, he summarized the six functions of an artificial floating island - preventing dike erosion, protecting coastlines, providing habitat for wildlife, beautifying landscape, purifying and filtering water and providing bilogical sterilization. In China, Song et al. [9] carried out research and application of artificial floating beds in the early 1990s. Huang et al. [10] studied making artificial floating beds by planting scindapsus aureus, canna and monstera deliciosa to remove nitrogen, phosphorus and organic pollutants. Yan Yixin et al. studied the dynamic purification effect of the floating bed technology on heavily polluted river water in winter and spring. Yan et al. [11] studied the purification effect of the combined process of biological purification tank and enhanced ecological floating bed on rural domestic sewage in Chongming Island, and found that the enhanced ecological floating bed deeply purifies the organic matters degraded in the biological purification tank to further remove nitrogen and phosphorus in the seage. Based on the experience of the Taihu Lake, Yunnan Research Academy of Eco-environmental Sciences planted plants with foam as the carrier of the floating island to purify water [12]. There are also many case studies on floating beds, all of which have achieved good results.

\section{ANALYSIS OF PRODUCT REQUIREMENTS}

\subsection{Requirements for water surface leisure platform due to water area tourism development}

With the accelerated global urbanization process, the tourism industry is booming. To meet the increasing tourists 
demands [13]. Countries have shifted their focus from building water conservancy projects to promoting water conservancy tourist activities and landscape construction [14]. It is an inherent nature of human to be close to water [15]. While satisfying people's basic needs for life, water also attracts people with its touch, appearance and sound [16]. For example, waterfront landscape has a lasting appeal to people. So it would be a great market opportunity to design and develop waterfront tourism products that can meet the changing market demands. The water surface leisure platform, as a kind of waterfront tourism product, can not only meet the needs of tourists for entertainment, but also serve as the access to activities on water surface. Therefore, surface leisure platform products with high modularity, fast installation and wide application range will gradually become the focus of research and also the rigid need of the market.

\subsection{Requirements for water surface leisure platforms due to sustainable development}

Many places where water area tourism is being developed choose economy over ecology, which is causing great damages to the overall environment. The global ecological crisis has prompted people to rethink the relationship between man and nature. Water environment is an important carrier for human survival and development [17]. To restore the water environment, humans have made many explorations. Multifunctional water surface leisure platform products that can meet the needs of future water area tourism development and coordinate the relationship between man and water will definitely become what is needed to keep the industry developing in a sustainable manner.

\section{COMPARISON OF EXISTING TRADITIONAI WATER SURFACE LEISURE PLATFORMS}

A water leisure platform is an unpowered or powered platform structure that extends to the water surface for the purpose of catering, entertainment, sightseeing and vacation tour. Floating platforms built on the basis of the floating boxes are known to have the most practical values due to their simple installation and low costs. The floating boxes (Figure 1) that compose this type of platform are connected with large-headed mushroom nails to form a relatively primary water surface platform (Figure 2). However, this kind of platform is simply structured and has only a single function. The space in the internal cavities of the main body is not well utilized and there is no additional ecological benefit. Moreover, due to its light weight and simple unit connection structure, the whole platform does not have high floatation stability and can only be applied in water areas with still water surfaces or where the wind wave ranges mostly between Grade 2-3.

A traditional floating box without packaging usually has a volume of $0.1 \mathrm{~m}^{3}$, and 4 floating boxes are required to cover each $1 \mathrm{~m}^{2}$ of water surface, which means at least $0.4 \mathrm{~m}^{3}$ of floating boxes are required for transportation to cover $1 \mathrm{~m}^{2}$ (Figure 3). In actual transportation, the volumes of the buffer areas between supporting structural members and floating boxes and between floating boxes and outer packaging should also be taken into account. A large-scale water leisure platform would require hundreds or even thousands of floating boxes. Due to the large packaging volume, transportation costs are often higher.

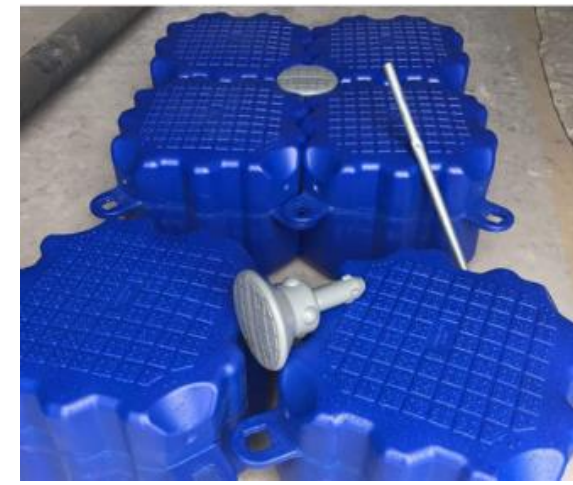

Figure 1. Traditional floating box

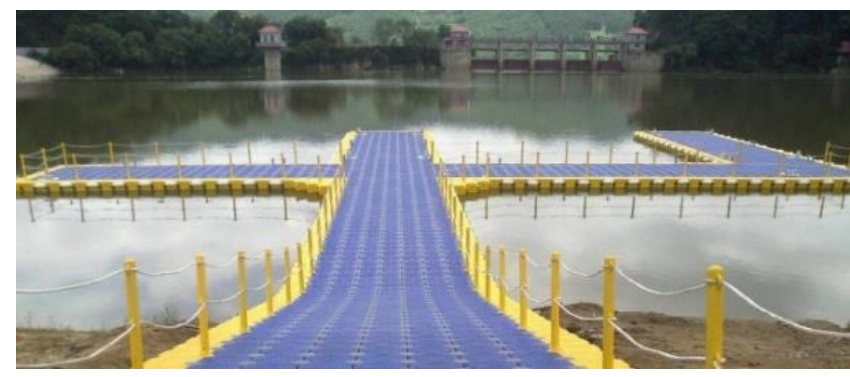

Figure 2. Traditional floating platform

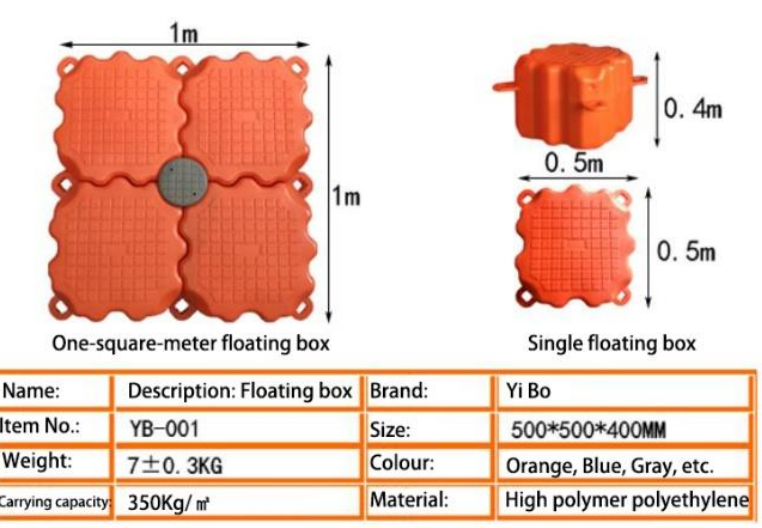

Figure 3. Parameters of a traditional floating box

Therefore, the design of the basic construction components of water leisure platforms for water area tourism should be optimized to increase the stability of floating boxes, improve space utilization, reduce transportation volume and achieve additional ecological benefits. The structural members should be modularized and light weighted and made of environmental-friendly materials.

\section{PREMISES FOR WATER SURFACE LEISURE PLATFORM DESIGN}

\subsection{Functional expansion}

Among the current problems in the development of water area tourism, restoration of ecological function is the top priority, so this paper attempts to optimize the design of the basic floating boxes for floating leisure platforms. The ecological floating bed technology that uses aquatic higher plants to purify water and restore ecological environment has been proved and widely used [18-21]. Currently, ecological 
floating beds can be divided into the wet type and the dry type depending on whether plants are exposed to water. Wet floating beds can be further divided into framed and frameless beds. A wet framed floating bed generally uses PVC pipes as the frame, and the polystyrene board as the planting bed body. Having higher stability than the frameless floating bed and better water purification effect than the dry floating bed, this type of ecological floating bed has been the most widely used $[22,23]$. In order to improve the water purification and restoration effect of ecological floating beds, various artificial intervention technologies have also been applied, such as mixed planting of various kinds of aquatic plants and supplementary artificial substrate technology, etc. [24-29]. Artificial ecological floating bed technologies are now improving and maturing.

In view of the water purification and water beautification effects of ecological floating beds, this paper attempts to combine floating boxes and the framed wet floating bed in a modular manner. The optimized planting base of the floating bed is embedded at the bottom of a floating box so that the ecological floating bed becomes part of the floating box. When the floating box floats, it can use the plant root system on the internal ecological floating bed to adsorb suspended solids, which provides a place where microorganisms and other aquatic organisms can inhabit and multiply and also forms a green island on the water surface that beautifies the water environment [30]. This method can not only achieve the ecological function of the leisure platform, but also reduce the center of gravity of the entire floating box through the weight of the floating bed substrate and plants, thereby improving the floating stability of the platform. The space enclosed by the floating box shell can also protect the plants on the internal ecological floating bed, reducing the maintenance cost incurred by frequent plant replacement. Moreover, thanks to the strong bearing capacity and stability of the floating box structure, there are more choices of plants that can be planted on the ecological floating bed. After the plants become mature, they will be moved away from the water body, which will take away a large amount of pollutants from the water body, thereby improving water quality, creating better ecological and environmental conditions for the survival and reproduction of aquatic organisms, and making it possible to finally restore the water ecosystem [31].

\subsection{Material optimization}

The environmental friendliness of materials means they have low environmental load throughout their entire life cycles [32]. The outer shells of the floating boxes in the floating leisure platform are made of polylactic acid material. This material has good thermal stability, with a processing temperature of $170 \sim 230^{\circ} \mathrm{C}$, and has good solvent resistance. In addition to being biodegradable, it is also biocompatible, glossy and transparent with nice feel and heat resistance, and what is more, it is antibacterial and flame retardant [33]. These features meet the strength requirements of floating boxes without affecting the photosynthesis of internal plants (Figure 4). The polylactic acid raw material is fully renewable, without any pollution generated in the production process, and the product can be biodegraded, so it can be recycled in nature. All of these making the material an ideal green high polymer material [33]. In addition, the interface areas of the outer shells are coated with polycaprolactone to improve the impact resistance. Considering the costs, the core planting unit inside the floating box is made of two materials - the transparent top cover is made of polylactic acid, and the structural members such as tie rods and frames are made of high-density polyethylene. Considering the strength and lightweight requirements for the platform, and by reference to the reinforcec concrete structure in architecture design, the rod members adopt a composite structure with high-density polyethylene (HDPE) embedded with stainless steel frames (Figure 5).

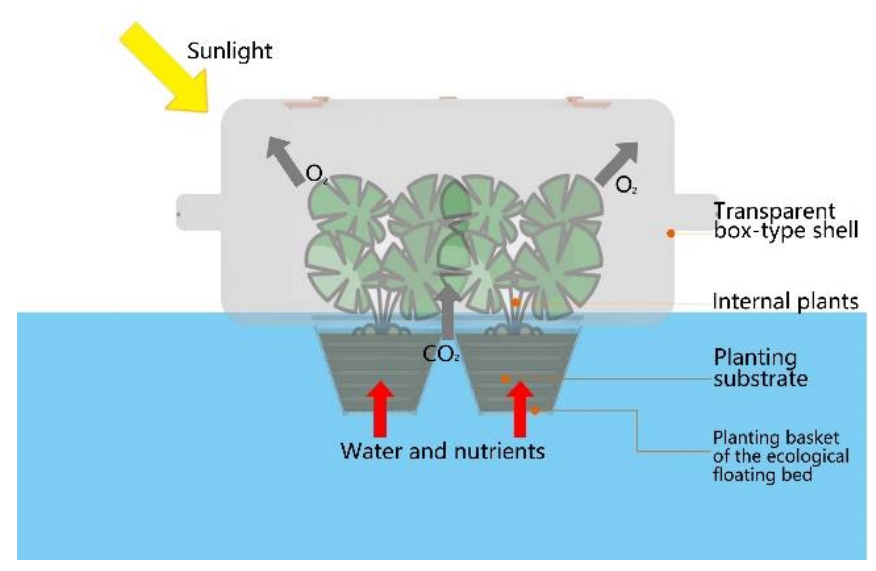

Figure 4. Design schematic

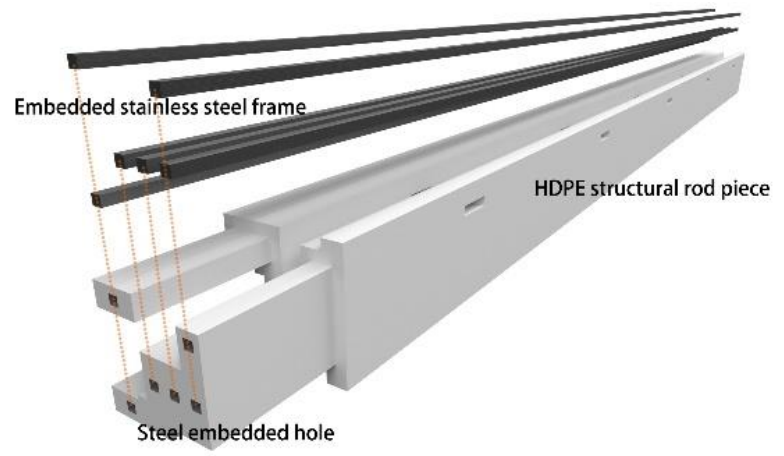

Figure 5. Schematic diagram of rod composite structure design

\subsection{Product modularization}

Modular design was first applied to the watch industry as a process design method. In the context of increasingly fierce market competition, modular design has become the leading method for large-scale customized design as it can achieve mass production, shorten the design cycle, save costs and resources, facilitate construction and be used for different purposes [34-36]. The existing floating leisure platform shows some modular idea, but overall, it is not sufficiently modular, the design of structural members is not mature, and the installation needs to be more convenient. Moreover, due to the process and design limitations, while obtaining high bearing capacity on the water surface, the huge cavity structure of the floating box also has problems such as low space utilization and high transportation costs. Therefore, both the main floating box and the structural members in the existing floating leisure platform can be further optimized based on the modularization concept to improve the applicability of the product and reduce transportation costs. 


\section{ANALYSIS OF THE WATER SURFACE LEISURE PLATFORM DESIGN}

The main components of a floating surface leisure platform can be divided into two parts: the basic floating box and the structural members. According to the new demands for water surface leisure platforms under the context of water area tourism development, it is decided that modular design be adopted to expand the product functions and improve the deficiencies of the original products (Figure 6).

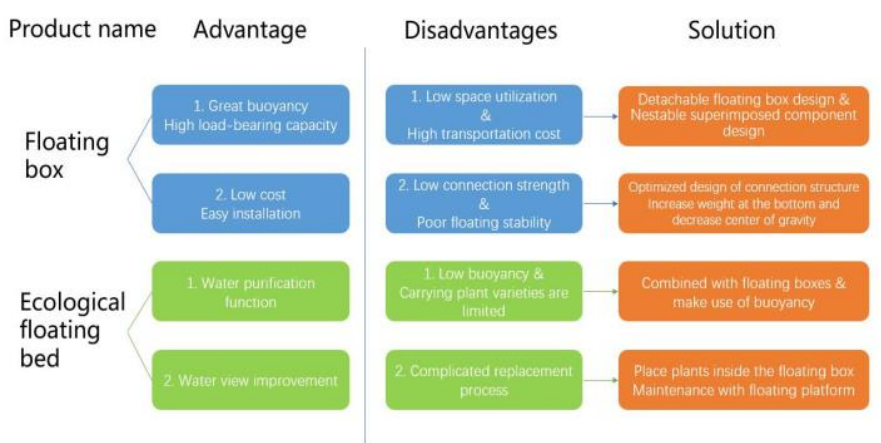

Figure 6. Design idea map

\subsection{Design of the basic floating box}

The modular design of the basic floating box involves modularization of components and modularization of functions. Components are modularized mainly to solve the problems like large transportation volume and high transportation cost of the original floating boxes and make the installation more convenient. To prevent too many types of floating boxes from increasing the installation complexity, only two types of basic units are designed as the basic buoyancy units, both being of the cubic shape. According to the differences in external interface, they are named Type A buoyant box and Type B buoyant box (Figure 7). The specific parameters are shown in Table 1. These buoyant boxes are adaptable to and expandable in a variety of scenarios, and the ports are adjusted accordingly to effectively improve construction convenience [37].

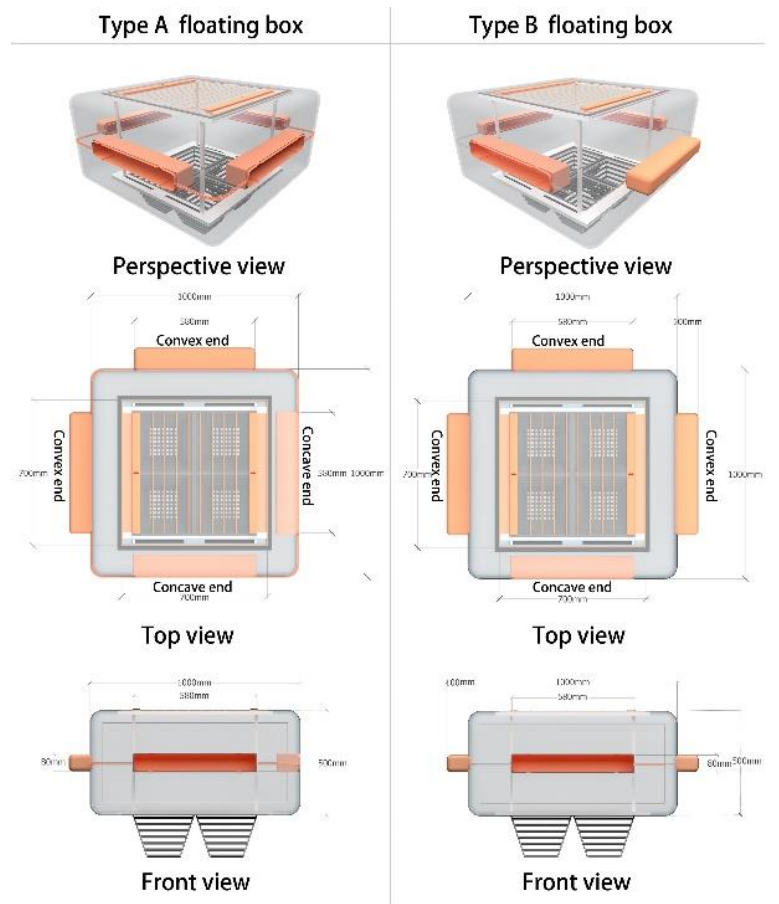

Figure 7. Type A floating box and Type B floating box

Table 1. Parameters of the external box of a floating surface leisure platform

\begin{tabular}{|c|c|c|c|c|c|}
\hline Description & Parameter & Main structure size & Material & Weight & Interface \\
\hline \multirow{3}{*}{ Type A floating box } & Length & $1000 \mathrm{~mm}$ & \multirow{3}{*}{$\begin{array}{l}\text { Polylactic acid (box body) } \\
\text { Polycaprolactone (interface) }\end{array}$} & \multirow{3}{*}{$700 \mathrm{~g} \pm 5 \mathrm{~g}$} & $580 \mathrm{~mm} * 40 \mathrm{~mm} * 100 \mathrm{~mm}$ \\
\hline & Width & $1000 \mathrm{~mm}$ & & & 2 concaves \\
\hline & Height & $500 \mathrm{~mm}$ & & & $\begin{array}{c}580 \mathrm{~mm} * 40 \mathrm{~mm} * 100 \mathrm{~mm} \\
2 \text { convexes } \\
\end{array}$ \\
\hline Type B floating box & Length & $1000 \mathrm{~mm}$ & $\begin{array}{l}\text { Polylactic acid (box body) } \\
\text { Polycaprolactone (interface) }\end{array}$ & $700 \mathrm{~g} \pm 5 \mathrm{~g}$ & $\begin{array}{c}580 \mathrm{~mm} * 40 \mathrm{~mm} * 100 \mathrm{~mm} \\
1 \text { concave } \\
580 \mathrm{~mm} * 40 \mathrm{~mm}^{*} 100 \mathrm{~mm} 3 \text { convexes }\end{array}$ \\
\hline
\end{tabular}

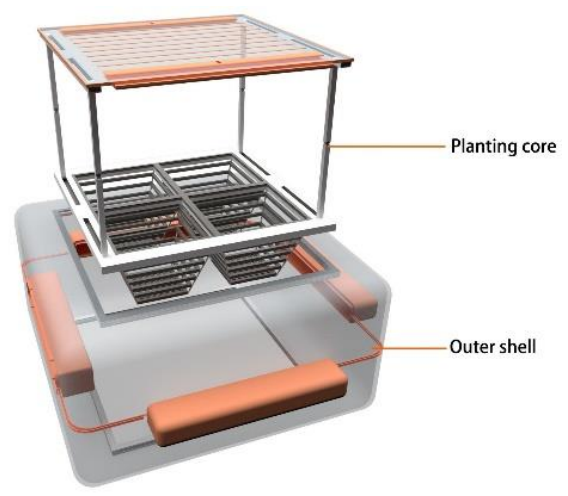

Figure 8. Schematic diagram of the combination of the outer shell and the planting core

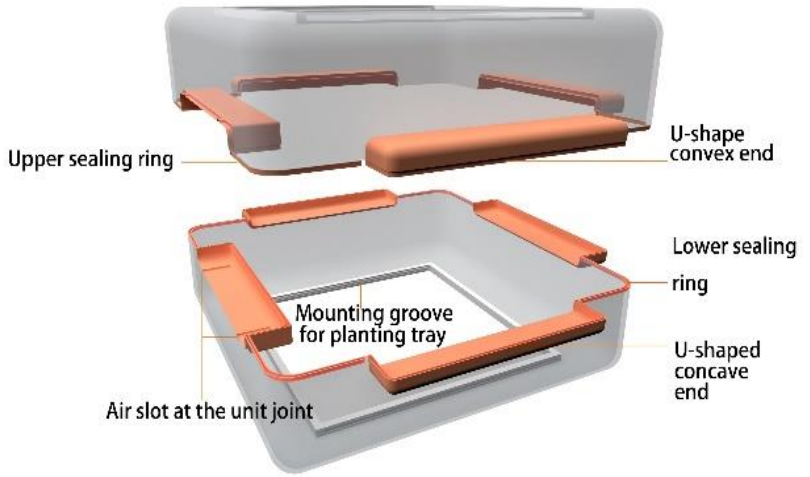

Figure 9. Schematic diagram of outer shell disassembly 


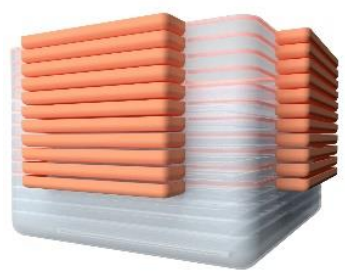

Side view of the stack

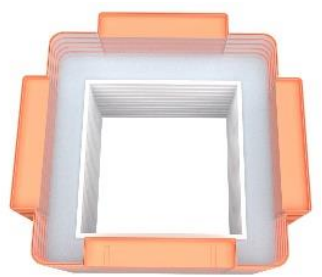

Top view of the stack
Figure 10. Schematic diagram of stack of half box modules in the outer shell

The modularization of functions is to design the basic compnents of the outer shell of the floating box to satisfy the floating load, and designing the core inside the floating box as an independent component with other functions. A floating box is formed by the outer shell embedded with the internal planting core (Figure 8), and the two parts are independent of each other. The outer shell of the floating box adopts the detachable design to reduce the packaging volume (Figure 9), as the components can be stacked during the transportation (Figure 10).

The internal planting core is mainly composed of the top cover plate (Figure 11), the middle tie rod and the bottom planting tray (Figure 12). The specific parameters are shown in Table 2. The buckle bars move in the grooves of the top cover along the horizontal direction and form an occlusal relationship with the corresponding grooves on the outer shell, so as to realize the engagement and disengagement between the planting core module and the outer shell (Figure 12). The planting basket in the bottom planting tray is composed of a PVC frame and a protective net inside (Figure 13). The highdensity protective net can not only prevent the planting substrate from leaking and polluting water, but also allow external water to penetrate inside normally. The hollow frame design increases the contact area between the plants and water, and the substrate made of high polymer material achieves synergy between substrate adsorption and plant absorption [38]. The planting core can reduce its vertical height by bending the rods and folding the planting basket, and finally become a compact flat disc-shaped unit (Figure 14). The volume of the entire core unit is $0.245 \mathrm{~m}^{3}$ before folding, and $0.022 \mathrm{~m}^{3}$ after folding, indicating that the structure is highly modular, with a high space utilization rate.

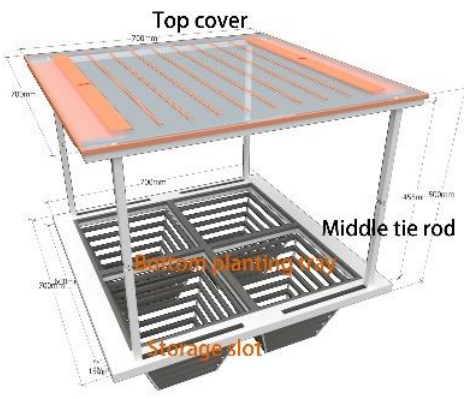

Figure 11. Internal planting core

Table 2. Planting core parameters

\begin{tabular}{ccccc}
\hline Description & Parameter & Size & Material & Weight \\
\hline \multirow{3}{*}{ Top cover } & Length & $700 \mathrm{~mm}$ & Polylactic acid & $255 \mathrm{~g} \pm 5 \mathrm{~g}$ \\
& Width & $700 \mathrm{~mm}$ & Polycaprolactone & \\
& Height & $28 \mathrm{~mm}$ & High density polyethylene & $50 \mathrm{~g} \pm 5 \mathrm{~g}$ \\
\multirow{2}{*}{ Middle tie rod } & Length & $15 \mathrm{~mm}$ & \\
& Width & $15 \mathrm{~mm}$ & & $395 \mathrm{~g} \pm 5 \mathrm{~g}$ (empty) \\
& Height & $455 \mathrm{~mm}$ & High density polyethylene & $2500 \mathrm{~g} \pm 10 \mathrm{~g}$ (containing substrate) \\
\hline \multirow{2}{*}{ Bottom planting } & Length & Width & $700 \mathrm{~mm}$ & \\
\hline
\end{tabular}

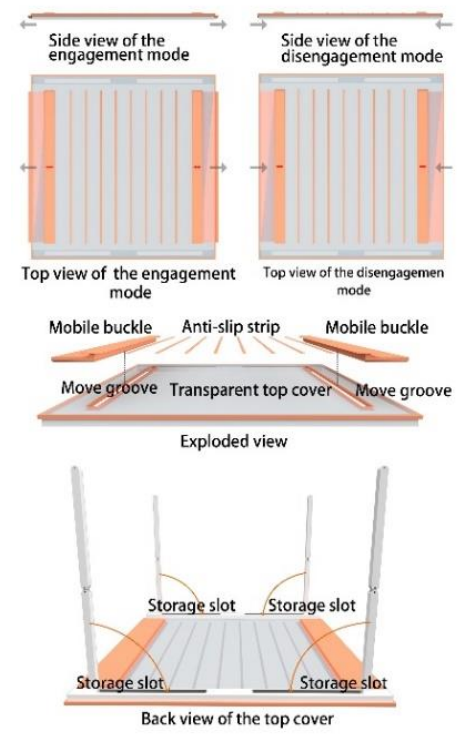

Figure 12. Schematic diagram of the top cover structure

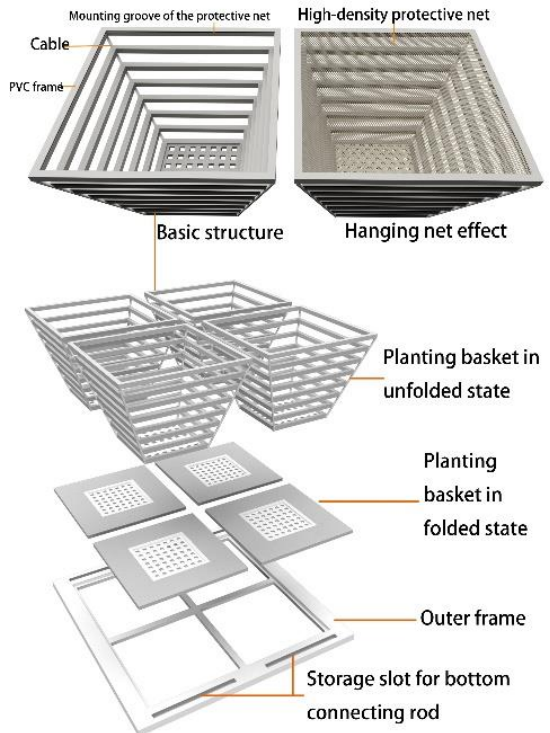

Figure 13. Planting tray 

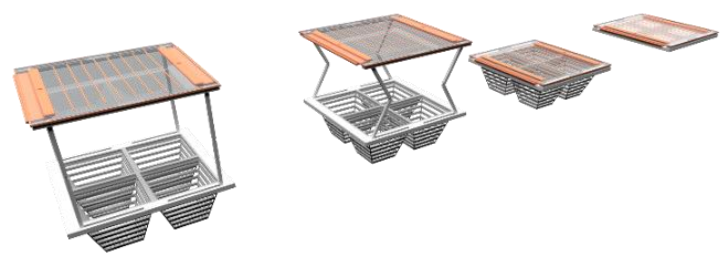

Figure 14. Schematic diagram of core module folding

\subsection{Design of supporting structural members}

The floating box-based floating surface leisure platform needs to supported by fixing structural members to enhance stability and safety. The supporting structural members are all designed in a modular way, so that they can be flexibly assembled to form water leisure platforms of different shapes and areas according to the specific requirements of the construction scene. The supporting structural members are mainly divided into two categories: floating box fixing members and platform fixing members. The former can be further divided into four parts: side rods, convex-end rods, concave-end rods and width-extension rods (Figure 15). A side rod consists of a side rod body, standard-length railing and railing fasteners. The platform fixing members can be divided into two parts - the cable fixing devices on the platform and the shore piles on the ground (Figure 15). The specific parameters of each structural member are shown in Table 3.

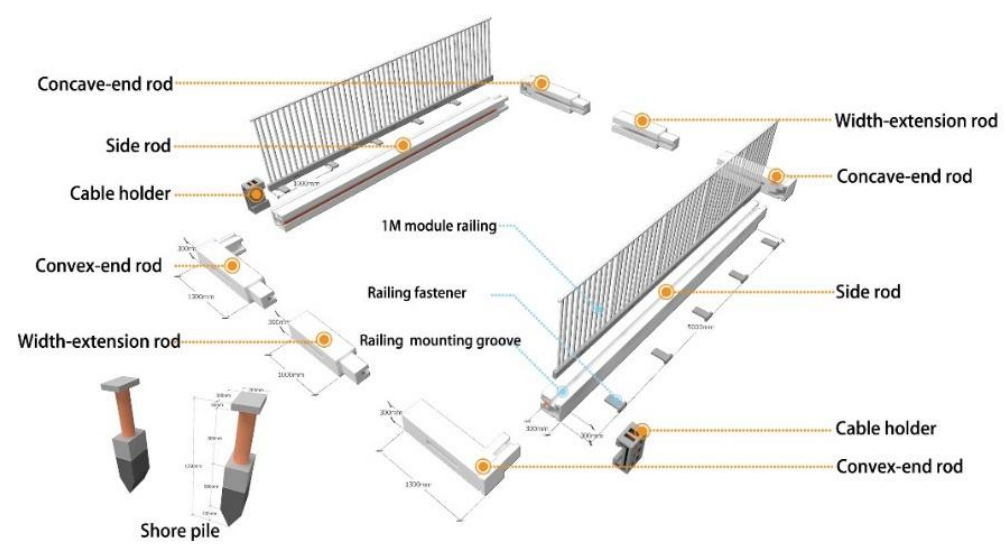

Figure 15. Supporting structural components

Table 3. Parameters of structural members

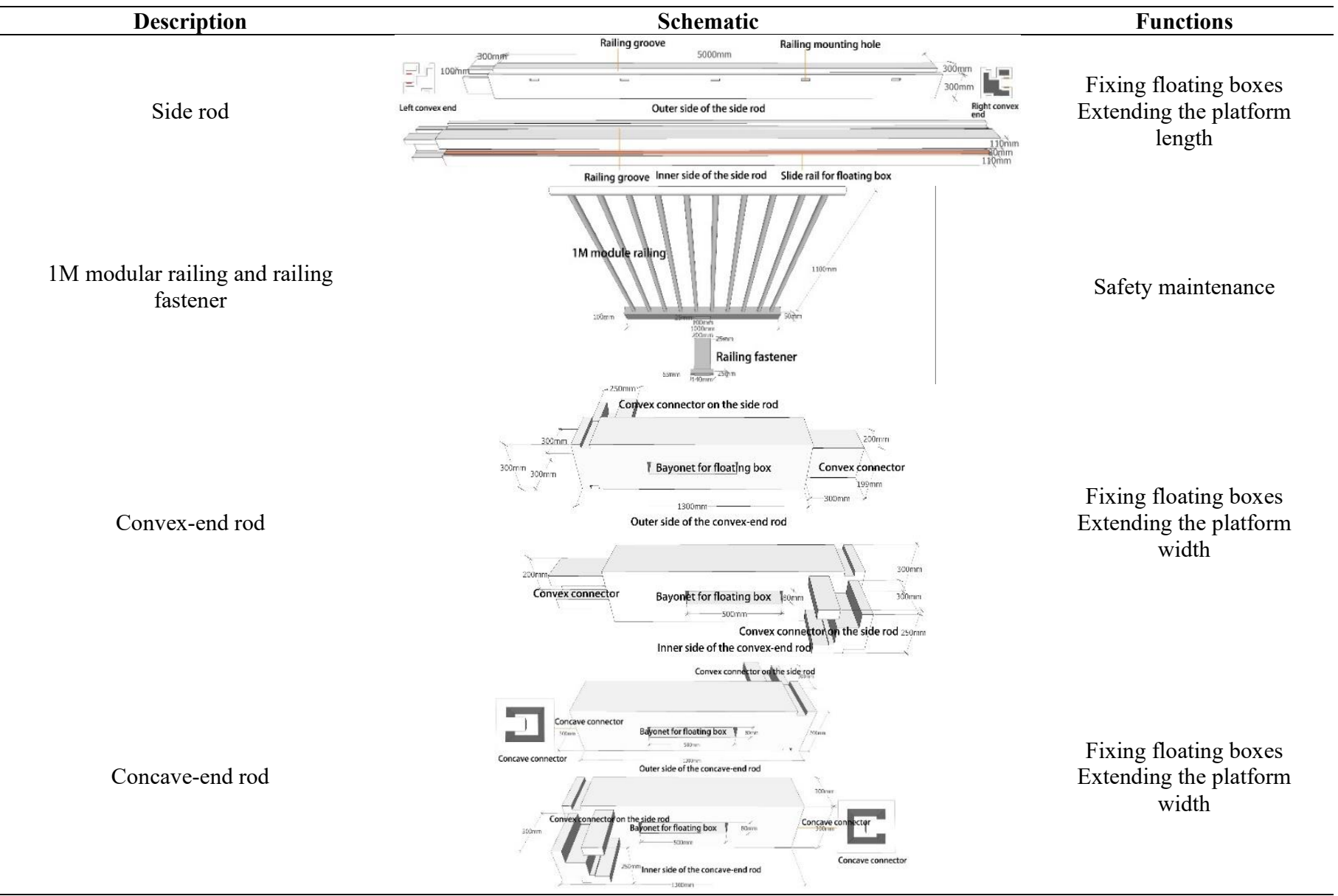


Width-extension rod

Cable holder

Shore pile
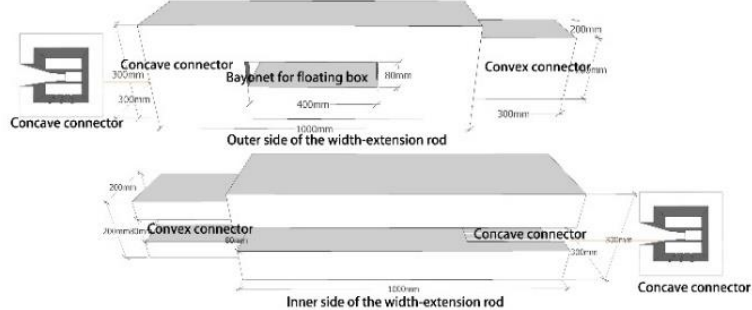

Inner side of the width-extension rod
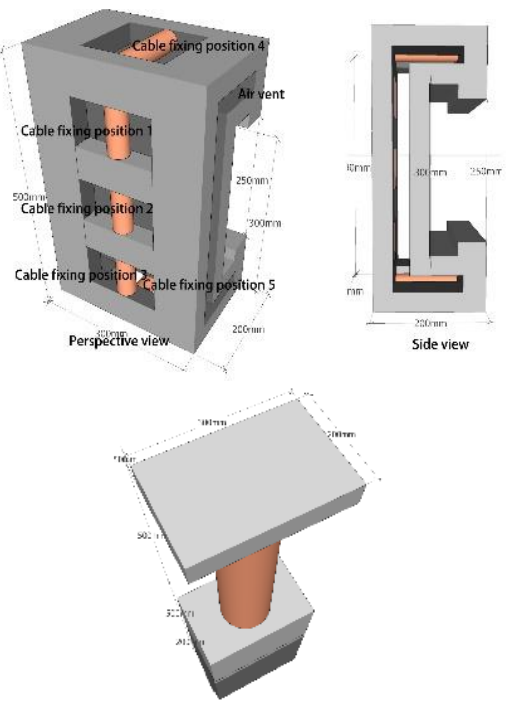

Fixing floating boxes Extending the platform length

Fixing the platform

Fixing the platform

\subsection{Platform installation process}

Floating surface leisure platforms can be set up quickly on the water surface. Take a water surface platform with a width of $3 \mathrm{~m}$ and a length of $10 \mathrm{~m}$ for example. Combine two Type A floating boxes and one Type $\mathrm{B}$ box into a basic row of floating boxes with a length of $3 \mathrm{~m}$ and a width of $1 \mathrm{~m}$ (Figure 16), and prepare 10 basic rows like this for later use. Assemble two concave-end rods and a width-extension rod into a $3 \mathrm{~m}$-wide rod piece. Connect one side rod with the cable holder preinstalled on each end of the rod piece to form a pocket-shaped cavity area. Push the pre-assembled rows into the enclosed cavity area one by one along the bayonet of the side rod, and install the modular railings in the same way into the upper groove of the side rod (Figure 17). After the floating box modules fill up the first set of side rods, connect the second set of side rods and form a new cavity area with the last batch of floating box modules. Then continue to install floating box rows in the new cavity area until it is filled up. Install a $3 \mathrm{~m}$ long rod piece consisting of two convex-end rods and one width-extension rod at the end of the second set of side rods to close the pocket-shaped filling area, so that the floating boxes are fixed within a stable quadrilateral rod structure (Figure 18), forming a floating platform. Finally, fix the shore piles on the land near the target water surface, connect the shore piles and the cable holders on the platform with cables, push the platform into water and adjust the length of the cable until the platform is stable. Then the installation is complete (Figure 19).

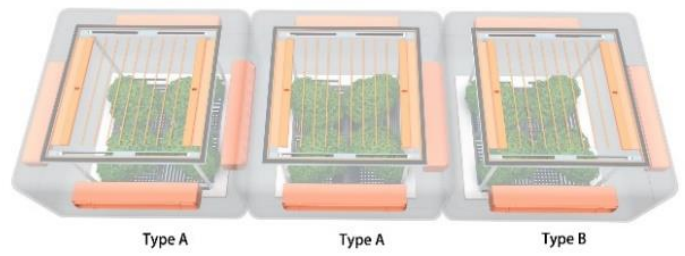

Figure 16. Basic row

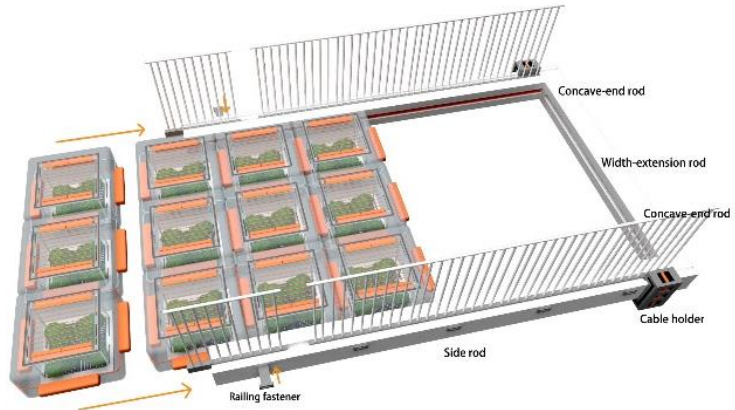

Figure 17. Installation process diagram

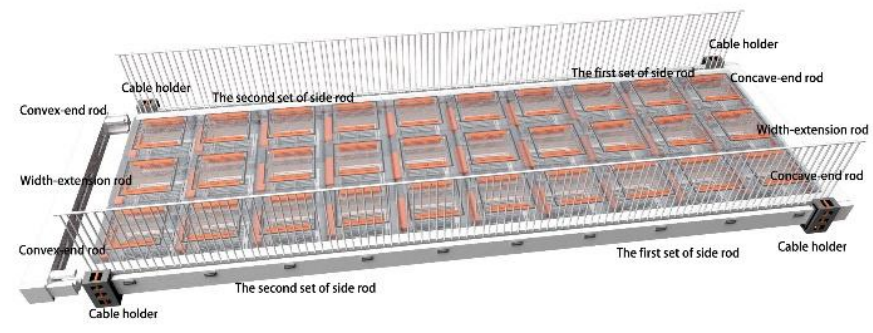

Figure 18. Installation process diagram

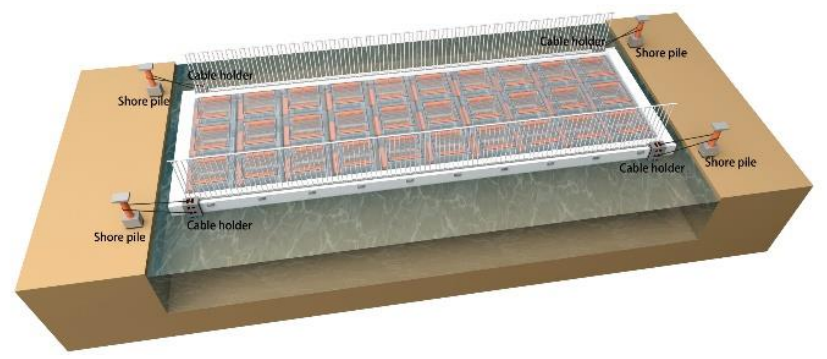

Figure 19. Installation process diagram 


\subsection{Main technical parameters}

When the water surface leisure platform is in the free floating state, the propagation of waves drives the flow field near the floating platform to change, so waves are the main reason for the movement of the floating platform on the water surface [39]. The design values of the components of the leisure platform are first determined in accordance with the safety and stability requirements of water surface activities, and then the strength and rigidity of the platform components (basic floating boxes and structural rod pieces) are checked to determine the final dimensions.

According to the design adaptive velocity of $\leq 3.6 \mathrm{~m} / \mathrm{s}$, the maximum allowable load of $500 \mathrm{~N} / \mathrm{m}^{2}$ and the full-load submersed height of $0.5 \mathrm{~m}$, the water flow impact pressure on the floating plate is calculated using the following formula: $R=K A \frac{\gamma V^{2}}{2 \mathrm{~g}}$, where $R$ represents the water flow impact pressure $(\mathrm{KN}) ; K$ represents the water flow resistance coefficient, for which the distribution coefficient $\mathrm{K}_{\mathrm{b}}$ of the bottom and side shear stress on the wall should be taken into account, so the value of the rectangular cross-section flow coefficient $K=1+K_{b}=1.3$ ( $K_{b}$ is a fixed coefficient of the side and bottom stress on the water flow in the rectangular cross section at the design adaptive velocity); $\gamma$ represents the water bulk density, which is set at $10 \mathrm{KN} / \mathrm{m}^{2} ; \mathrm{g}$ represents the gravity acceleration, which is set at $9.81 / \mathrm{S}^{2} ; V$ indicates the calculated water velocity, which is set at $V=3.6 \mathrm{~m} / \mathrm{s}$ during construction; and $A$ indicates the projected area of the part of the floating plate in water in the vertical water flow direction.

Substitute the data into the above formula, and we have $R=5.96 \mathrm{KN}$. If a standard section is $5 \mathrm{~m}$ long and $3 \mathrm{~m}$ wide, and 15 floating box modules are needed, then the resultant water impact force is $89.4 \mathrm{KN}$.

Calculate the water flow pressure on the side rail of a standard section of the floating platform: $R_{\mathrm{g}}=K A \frac{\gamma V^{2}}{2 \mathrm{~g}}=$ $1.3 \times 1.8 \times \frac{10 \times 9}{2 \times 9.81}=10.73 \mathrm{KN}$. A single section of the floating boxes is connected to the rails of the side rods on the two sides. Check the strength and rigidity: $q=$ $\frac{178.90-10.73 \times 2}{2 \times 0.3 \times 6}=43.73 \mathrm{KN} / \mathrm{m}$.

Check the strength: $M_{\max }=\frac{q l^{2}}{8}=\frac{43.73 \times 6^{2}}{8}=196.79 \mathrm{KN} \cdot \mathrm{m}$ and $\delta=\frac{M_{\max }}{W}=\frac{196.79 \mathrm{KN} \cdot \mathrm{m}}{\left(7.625 \times 10^{6} \mathrm{~mm}^{3}\right)}=25.8 \mathrm{Mpa}$, which is smaller than $[\delta]$, indicating the strength meets the requirement.

$$
\text { Check the rigidity: } \quad f_{\max }=\frac{5 q l^{4}}{384 E I}=
$$
$\frac{5 \times 43.73 \times 6^{4} \times 10^{12}}{384 \times 195000 \times 1.57 \times 10^{9}}=2.41 \mathrm{~mm}$, which is smaller than $[f]$, indicating that the rigidity meets the requirement.

During the use of the floating leisure platform, due to the inertial forces and impacts from the movements of facilities, personnel and equipment, the platform may be out of balance and tilted. Therefore, the platform design needs to make sure the platform will not overturn after tilting due to external interferences, and that it can return to the original balanced position after the external force disappears, that is, it is able to resist external forces [40]. This paper mainly considers the horizontal stability of the platform [41], which requires the calculation of the restoring moment of the platform when it tilts at a certain angle [42]. In the stability analysis of this paper, the platform is considered as a rigid body. The platform is set to be $40 \mathrm{~m}$ long and $20 \mathrm{~m}$ wide, and the weight of facilities and personnel is $1000 \mathrm{~kg}$. The equal displacement of the platform floating box is shown in Figure 20. From the main visual plane, the calculated center of gravity $G$ is $(0,0.2856 \mathrm{~m})$. Suppose the center of gravity of the platform remains unchanged, $A B$ is the waterline in the initial balanced state [43], the part of the platform below the waterline is the submersed part, the submersed height is $0.154 \mathrm{~m}$, and the center of buoyancy is $P$. When the heel angle is $\alpha$, the waterline is $\mathrm{A}^{\prime} \mathrm{B}^{\prime}$, and the center of buoyancy is $P^{\prime}$. According to the formula:

$$
\begin{aligned}
& l=P^{\prime} E=P^{\prime} D \cos \alpha=\left(P^{\prime} C-D C\right) \cos \alpha \\
& =-x_{P^{\prime}} \cdot \cos \alpha+\left(y_{P^{\prime}}-y_{G}\right) \sin \alpha
\end{aligned}
$$

Calculate the righting arm $l$. According to the formula:

$$
M=m g l
$$

Calculate the restoring moment $M$ using MATLAB [44]. When the heel angle $\alpha$ increases from $0^{\circ}$ to $60^{\circ}$, the change of the restoring moment is shown in Figure 21. According to the calculation results, when the heel angle $\alpha=8.9^{\circ}$, the restoring moment reaches its maximum value, which is about 13,158 $\mathrm{kN} \cdot \mathrm{m}$.

However, in the actual process, the heel angle of the floating platform is small. Assuming that the right side of the platform reaches the critical point of water surface, the heel angle $\alpha=0.443^{\circ}$. Figure 22 shows the curve of the restoring moment of the floating platform when the heel angle changes between $0^{\circ}-0.443^{\circ}$. It can be seen that when the heel angle is small, the restoring moment is approximately proportional to the heel angle [44]. When the heel angle $\alpha=0.443^{\circ}$, the restoring moment $\mathrm{M}=6374 \mathrm{kN} \cdot \mathrm{m}$. The maximum restoring moment caused by the weight of facilities, personnel and the platform is $1352 \mathrm{kN} \cdot \mathrm{m}$, which is within the safety range of the horizontal stability for the platform.

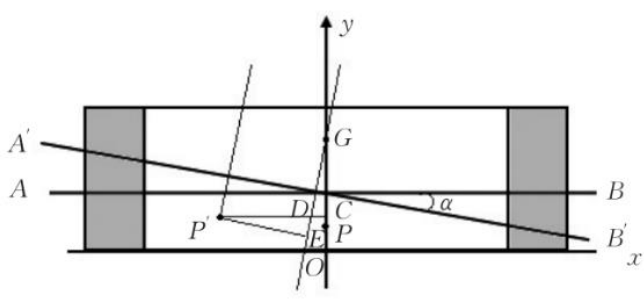

Figure 20. Cross section of the platform after tilting

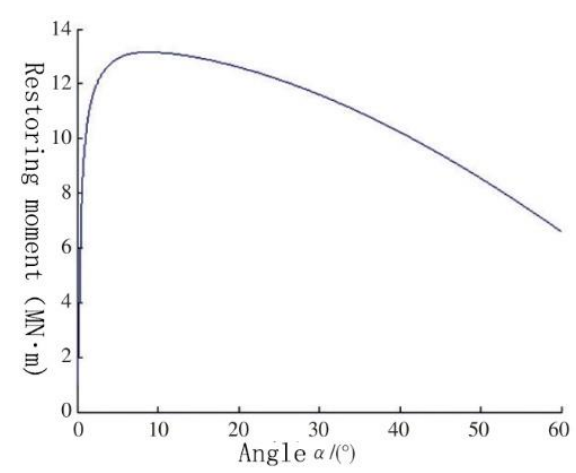

Figure 21. Relationship between the restoring moment and the heel angle after the platform tilts 


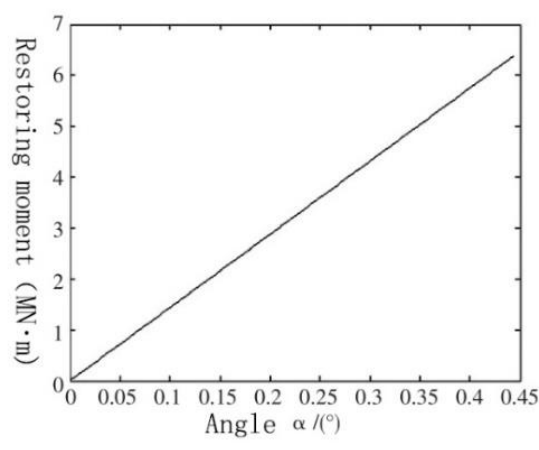

Figure 22. Curve of the restoring moment when the heel angle is small

\subsection{Principles for plant selection}

Plants in the floating boxes should be selected based on not only the growth adaptability and the nutritive salt removal efficiency of the floating bed plants [45], but also other factors such as their allelopathic effect [46]. Due to the height limitation of the internal space in the floating boxes of the floating leisure platform, aquatic plants with lower growth heights are the better choices. According to the structural characteristics of the box-type floating bed, emergent aquatic plants with roots and stems of the plants in the bottom mud of the water, and branches and leaves out of the water are preferred [47]. The first thing to note is the plants' absorption capacity of nitrogen and phosphorus and adaptability to changes in water level to ensure that the system can operate stably in rainy and dry seasons. The second is the activity and decontamination capacity in cold areas and seasons. Thanks to the transparent shell of the box structure, the plants can grow as if they were in a relatively stable environment, which expands the application scope of the floating boxes. The third is how well the roots, stems and leaves are developed, as these parts help the plants absorb nutrients, thus enhancing the internal circulation and breathability of the ecosystem and improving water quality. The fourth is the ornamental value of the plants. In a large water area, different plants can be planted in different sections to form beautiful patterns on the water. Cultivating plants inside the cavities of the floating boxes restrict the growth of plants to some extent due to the limited space, but it also avoids many problems that may arise from the disorderly growth of plants on the water surface.

\subsection{Subsequent operation and maintenance methods}

The subsequent maintenance of the leisure platform is simple. After the plants enter the decay period, the decomposition of plant residue can easily cause secondary pollution of the water body. After the internal plant growth cycle is over, open the mobile buckle on the outer shell and vertically take out the planting core to clean up the decaying plant residues. And at the same time, replace the planting basket in the bottom with a new one and put it into the outer shell.

During the maintenance period, personnel can operate on the floating platform without using any auxiliary vehicles. When the upper cover of a floating box is opened for replacement of plants, causing it to lose its buoyancy, other unopened floating boxes around it will still provide buoyancy (Figure 23). According to the buoyancy formula ( $F_{\text {floating }}$ ${ }_{b o x}=\rho_{\text {liquid }} * g * V_{\text {displacement }}$, under standard conditions, a single floating box with a weight of $3.7 \mathrm{~kg}$ has a gravity of $37 \mathrm{~N}$, and the standard draught is $0.037 \mathrm{~m}$ under dead weight without any external load. Under full load, the draught is $0.5 \mathrm{~m}$, and the displacement volume is $0.5 \mathrm{~m}^{3}$, so the maximum buoyancy provided by each unit is about $500 \mathrm{~N}$. After deduction of the gravity of the unit, which is $37 \mathrm{~N}$ (due to the dead weight of the unit $3.7 \mathrm{~kg}$ ), the actual maximum buoyancy is $463 \mathrm{~N}$. Therefore, according to the changes of draught caused by the changes of load, the buoyancy of a single floating box fluctuates between $37-463 N$. In theory, when the full-load buoyancy of the effective floating box units composing the floating platform is greater than the maintenance load gravity (the weight of all floating boxes + external force), it will be safe to carry out the maintenance operations. Assuming that the external force is $1000 \mathrm{~N}$ and there are $\mathrm{n}$ floating boxes, according to the formula $463 *(n-1)>37 * n+1000$ ( $n$ is an integer), the number of floating boxes supporting safe maintenance under this condition is 3.2 , which indicates that, in theory, a combination of 4 or more floating boxes will be sufficient for maintenance operations. In actual application, considering factors such as weight gain of internal plants during growth and water surface fluctuations, the minimum number of floating boxes for maintenance operations should be appropriately increased.

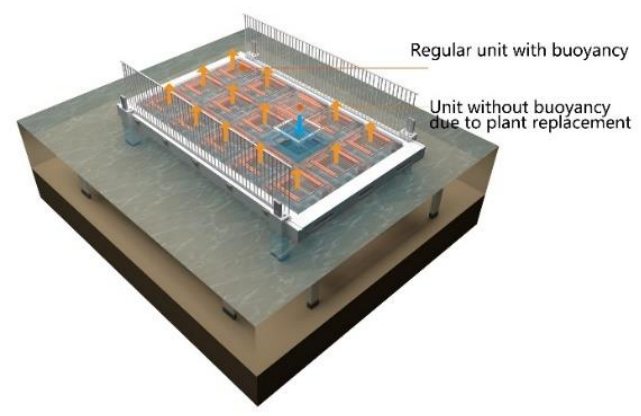

Figure 23. Schematic diagram of plant replacement

Once the leisure platform is laid and maintained on a regular basis, it will work as an ecological leisure platform for providing access, purifying water quality and sightseeing (Figure 24-25). In areas with plans to develop high-end water area tourism, this product can be used to replace the simple leisure platform built of the original floating boxes so that tourists can carry out water activities while enjoying the beautiful sight there. At the same time, the platform can also maintain the water environment to some extent.

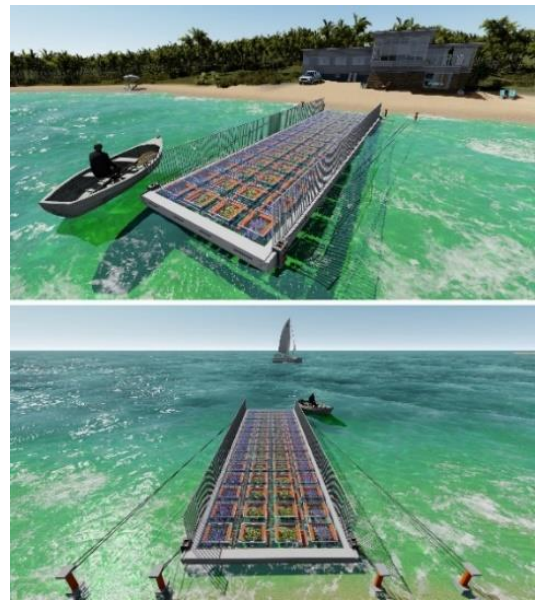

Figure 24. Surface access platform 


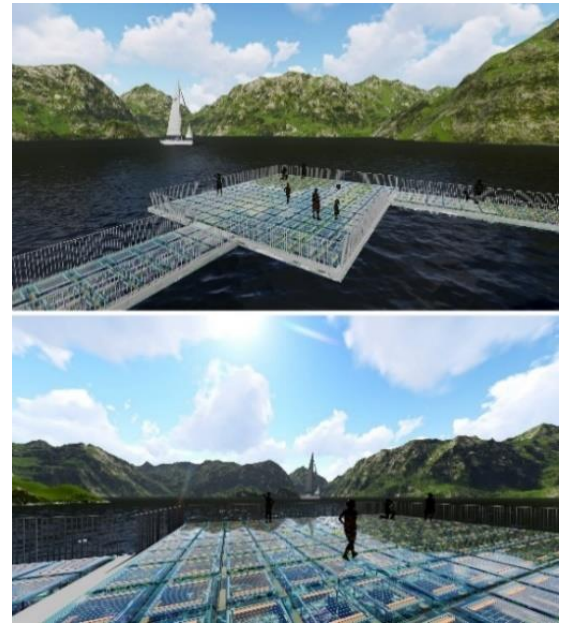

Figure 25. Eco-tourism platform

\section{CONCLUSIONS}

This paper designs a floating surface leisure platform in a modular way, in an attempt to make it a composite platform with ecological added values. In the future, the design can be further optimized according to the development needs of the water area resources to make the leisure platform multifunctional and adaptive to more application scenarios. In the face of the contradictions between development and resources protection, the modular design idea is a way to enhance the added values and social values of products and also to keep the sustainable development.

\section{ACKNOWLEDGMENT}

This work is supported by Chongqing Social Science Planning Project (2019YBSH085); Chongqing Higher Education Society Higher Education Scientific Research Project (CQGJ19B39); Chongqing Higher Education Teaching Reform Research Project (181010).

\section{REFERENCES}

[1] Cheng, Y.B. (2009). Analysis of Shanghai tourism economic resources and the influence of world expo. Market Weekly, (8): 31-33.

[2] Aas, Ø., Kaltenborn, B.P. (1995). Consumptive orientation of anglers in Engerdal, Norway. Environmental Management, 19(5): 751. https://doi.org/10.1007/BF02471957

[3] Schuett, M.A., Pierskalla, C.D. (2007). Managing for desired experiences and site preferences: The case of feefishing anglers. Environmental Management, 39(2): 164177. https://doi.org/10.1007/s00267-005-0366-0

[4] Alam, S.K., Ager, L.A., Rosegger, T.M., Lange, T.R. (1996). The effects of mechanical harvesting of floating plant tussock communities on water quality in Lake Istokpoga, Florida. Lake and Reservoir Management, 12(4):

$455-461$. https://doi.org/10.1080/07438149609354285

[5] Haller, W.T. (1996). Evaluati on of the Kelpin 800 aquatic weed harvester, Orange Lake, Florida1995. Aquatics, 18(3): 10-15.
[6] Mallison, C.T., Stocker, R.K., Cichra, C.E. (2001). Physical and vegetative characteristics of floating islands. Journal of Aquatic Plant Management, 39: 107-111.

[7] Sasser, C.E., Visser, J.M., Evers, D.E., Gosselink, J.G. (1995). The role of environmental variables on interannual variation in species composition and biomass in a subtropical minerotrophic floating marsh. Canadian Journal of Botany, 73(3): 413-424. https://doi.org/10.1139/b95-042

[8] Sasser, C.E., Gosselink, J.G., Swenson, E.M., Swarzenski, C.M., Leibowitz, N.C. (1996). Vegetation, substrate and hydrology in floating marshes in the Mississippi river delta plain wetlands, USA. Vegetatio, 122(2): 129-142. https://doi.org/10.1007/BF00044695

[9] Song, X.F., Zou, G.Y., Wu, W.M., Jin, Q.Y., Yin, H.D. (1998). Study on the removal effect and regulation of rice plants on floating-beds to main nutrients $n$ and $p$ in eutrophicated water bodies. Journal of Environmental Science, $18(5)$ : 489-494. https://doi.org/10.3321/j.issn:0253-2468.1998.05.008

[10] Huang, T.L., Song, L.T., Zhong, J.H., Xie, Y., Wang, X.C. (2007). Study on the urban scenic water purification by floating beds. Journal of Xi'an University of Architecture and Technology, 19(1): 30-33. https://doi.org/10.3969/j.issn.1006-7930.2007.01.005

[11] Yan, Y.X., Cao, J.S., Li, Y.R. (2006). Dynamic pilot study on purification of heavily polluted river water with floating bed technology in winter-spring. Journal of Hohai University Natural Science Edition, 34(2): 119-22. https://doi.org/10.3321/j.issn:1000-1980.2006.02.001

[12] Zhao, X.H., Tian, J. (2005). Research on man-made floating island technology applied in lake water treatment. Yunnan Environmental Science, 24(z2): 130$132 . \quad$ https://doi.org/10.3969/j.issn.16739655.2005.z2.041

[13] Wang, Y. (2008). Research on integrated development model of waterfront tourism in south Jiangsu province. Nanjing Normal University.

[14] Office of History, U.S. Army Corps of Engineers. (2003). History of the U.S. army corps of engineers. Stockton: University Press of the Pacific.

[15] Liu, R. (2016). Design study on the waterfront area of Guangzhou's old city based on the coordination between man and nature. South China University of Technology.

[16] Simonds, J.O. (1983). Landscape architecture-A manual of site planning and design. Mc Graw-Hill Book Company.

[17] Fang, M.Q. (2018). Comprehensive evaluation of water environment and landscape design of Yancheng City from the perspective of water ecological civilization. Inner Mongolia Environmental Sciences, 30(11): 183$184 . \quad$ https://doi.org/10.16647/j.cnki.cn151369/X.2018.11.107

[18] Li, M., Wu, Y.J., Yu, Z.L., Sheng, G.P., Yu, H.Q. (2007). Nitrogen removal from eutrophic water by floating-bedgrown water spinach (Ipomoea aquatica Forsk.) with ion implantation. Water Research, 41(14): 3152-3158. https://doi.org/10.1016/j.watres.2007.04.010

[19] Hu, G.J., Zhou, M., Hou, H.B., Zhu, X., Zhang, W.H. (2010). An ecological floating-bed made from dredged lake sludge for purification of eutrophic water. Ecological Engineering, 36(10): 1448-1458. https://doi.org/10.1016/j.ecoleng.2010.06.026

[20] Zhu, L., Li, Z., Ketola, T. (2011). Biomass 
accumulations and nutrient uptake of plants cultivated on artificial floating beds in China's rural area. Ecological Engineering, $\quad 37(10)$ : 1460-1466 https://doi.org/10.1016/j.ecoleng.2011.03.010

[21] Stewart, F.M., Muholland, T., Cunningham, A.B., Kania, B.G., Osterlund, M.T. (2008). Floating islands as an alternative to constructed wetlands for treatment of excess nutrients from agricultural and municipal wastesresults of laboratory-scale tests. Land Contamination \& Reclamation, 16(1): 25-33. http://dx.doi.org/10.2462/09670513.874

[22] Lettink, M., Cree, A. (2007). Relative use of three types of artificial retreats by terrestrial lizards in grazed coastal shrubland, New Zealand. Applied Herpetology, 4(3): 227-243. https://doi.org/10.1163/157075407781268336

[23] Pomeroy, E., Stock, J.T., Zakrzewski, S.R., Lahr, M.M. (2010). A metric study of three types of artificial cranial modification from north-central Peru. International Journal of Osteoarchaeology, 20(3): 317-334. https://doi.org/10.1002/oa.1044

[24] Billore, S.K., Sharma, J.K. (2009). Treatment performance of artificial floating reed beds in an experimental mesocosm to improve the water quality of river Kshipra. Water Science and Technology, 60(11): 2851-2859. https://doi.org/10.2166/wst.2009.731

[25] Lu, Z., Wei, W., Xu, Y.Y. (2009). Application of immobilized cell technology in wastewater treatment. Practical Technology, 29(7): 21-23. https://doi.org/10.3969/j.issn.1674-1021.2009.07.008

[26] Zheng, J., Ma, X.T., Zhou, L., Zhou, Q.Y., Wang, Z.Q., Wang, W.D., Yin, C.Q. (2011). Development characteristics of aquatic plants in a constructed wetland for treating urban drinking water source at its initial operation stage. Environmental Science, 32(8): $2247-$ 2253.

[27] Ma, H., Cui, F., Liu, Z., Fan, Z. (2009). Pilot study on control of phytoplankton by zooplankton coupling with filter-feeding fish in surface water. Water Science and Technology, 60(3): 737-743 https://doi.org/10.2166/wst.2009.437

[28] Li, X.N., Song, H.L., Li,W., Lu, X.W., Nishimura, O. (2010). An integrated ecological floating-bed employing plant, freshwater clam and biofilm carrier for purification of eutrophic water. Ecological Engineering, 36(4): 382 390. https://doi.org/10.1016/j.ecoleng.2009.11.004

[29] Finardi, S., Tinarelli, G., Faggian, P., Brusasca, G. (1998). Evaluation of different wind field modeling techniques for wind energy applications over complex topography. Journal of Wind Engineering and Industrial Aerodynamics, 74-76: 283-294. https://doi.org/10.1016/S0167-6105(98)00025-7

[30] Xia, P.H., Li, Q.H. (2011). Water environment and ecological restoration of measures at the inflow rivers of Hongfeng and Baihua reservoirs. Journal of Anhui Agricultural Sciences, 39(12): 7344-7346. https://doi.org/10.3969/j.issn.0517-6611.2011.12.155

[31] Deng, Z.Q., Yan, B.X., Li, X.H., Zhu, H. (2013). Research progress of application of artificial floating beds technology. Environmental Pollution and Prevention, $\quad 35(5)$ : $88-92$. https://doi.org/10.3969/j.issn.1001-3865.2013.05.019

[32] Zhang, Z.H., Wu, G.R. (2004). Concepts and rules of green products design. Packaging Engineering, 5(25): 108-119. https://doi.org/10.3969/j.issn.10013563.2004.05.045

[33] Cui, B.Y., Zhang, Z.F., Kong, Q. (2013). The application of natural biodegradable materials in agricultural field. Chinese Agricultural Science Bulletin, 29(24): 5-10.

[34] Lin, Y.Q. (2018). Make good use of modular organization model to seize the high end of strategic emerging industries. China Economic Guidbook. http://www.ceh.com.cn/epaper/uniflows/html/2018/07/2 7/06/06 34.htm

[35] Dong, H.H., Wang, W.W., Lv, M.M. (2017). Modular design of personalized customization model. Packaging Engineering, 38(6): 129-133

[36] Wang, H.J. (2005). Research on some design methods of product modularization for mass customization. Dalian: Dalian University of Technology.

[37] Dong, L.L., Chang, Q., Cheng, X. (2020). Design of modular enlightened children's water entertainment toys. Packaging Engineering, 41(2): 218-224. https://doi.org/10.19554/j.cnki.1001-3563.2020.02.033

[38] Liu, Y., Zou, G., Song, X., Fu, Z., Pan, Q., Liu, F., \& Fan, J. (2010). Effect of a new ecological floating bed system (EFBS) on phytoplankton community in eutrophicated water. Acta Hydrobiologica Sinica, 34(1): 196-203. http://dx.doi.org/10.3724/SP.J.1035.2010.00196

[39] Jiang, C.H. (2016). Research on disturbance analysis and control system of floating platform on the water surface. Nanjing University of Science and Technology.

[40] Sheng, Z.B., Liu, Y.Z. (2013). Principle of Naval Architecture. Shanghai: Profile of Shanghai Jiao Tong University Press.

[41] Wang, S.Q., Zhang, J.P. (2002). Stability of the ship being listing for a certain angle. Journal of Dalian Maritime University, 28(3): 31-33.

[42] Jiang, W.Q. (1999). Principle of naval architecture. Dalian: Dalian Maritime University Press.

[43] Tang, W.F., Sun, J. (2012). Research on the floating stability to the floating body. Journal of Naval Aeronautical and Astronautical University, 27(5): 521524.

[44] Xu, X.S., Li, Q., Yu, Q.A., Zhang, Z.Q., Wang, J. (2016). Structural design of operating platform when construction water is faced in the UHV river network area. Hubei Electric Power, 40(3): 34-40. https://doi.org/10.19308/j.hep.2016.03.008

[45] Liu, Y.Q., Zou, G.Y., Song, X.F., Fu, Z.S., Pan, Q., Liu, F.X., Fan, J.Q. (2000). Effect of a new ecological floating bed system (EFBS) on phytoplankton community in eutrophicated water. Acta Hydrobiologica Sinica, 34(1): 196-203. https://doi.org/10.3724/SP.J.1035.2010.00196

[46] Nakai, S., Zou, G., Okuda, T., Tsai, T.Y., Song, X., Nishijima, W., Okada, M. (2010). Anti-cyanobacterial allelopathic effects of plants used for artificial floating islands. Allelopathy Journal, 26(1): 113-122.

[47] Cao, Y., Sun, C.J. (2009). Application of ecological floating beds to water restoration and its design. Environmental Science and Technology, 2(2): 122. 